\title{
Antimicrobial Photodynamic Therapy: A New Therapeutic Option to Combat Infections
}

Luciano Pereira Rosa* and Francine Cristina da Silva

Multidisciplinary Health Institute, UFBA, Vitória da Conquista-BA, Brazil

*Corresponding author: Luciano Pereira Rosa; Multidisciplinary Health Institute, UFBA, Vitória da Conquista, Bahia, Brazil, CEP: $45027-500$; Tel.: +55 77 34292714; Email: drlucianorosa@yahoo.com.br

Rec Date: July 22, 2014, Acc date: August 24, 2014, Pub date: August 26, 2014

Copyright: (c) 2014 Rosa LP, et al. This is an open-access article distributed under the terms of the Creative Commons Attribution License, which permits unrestricted use, distribution, and reproduction in any medium, provided the original author and source are credited.

\begin{abstract}
Minimization or elimination of antibiotic resistance in microbial species is an urgent need of the present times. Antimicrobial photodynamic therapy is a new therapeutic option through which development of resistance in microorganisms can be avoided. Interest in the use of photodynamic therapy to combat microbial infection is not only linked to the fact that this technique prevents antibiotic resistance in microorganisms, but is also due to the broad-spectrum antimicrobial effect, selectivity, with little or no local or systemic side effects, to microorganisms, ease of application of the technique, among other beneficial features. In this review, the major aspects related to the use of antimicrobial photodynamic therapy with respect to the major photosensitizing dyes and light sources used in the therapy have been discussed. In addition, current applications, wherein the use of the technique has yielded successful results, have also been discussed along with the possibility of future applications of this new therapeutic option to combat infections.
\end{abstract}

Keywords: Antimicrobial photodynamic therapy; Dyes; LED; Laser

\section{Introduction}

The incorrect prescription and/or over-prescription of antibiotics for the treatment of every disease can be partially attributed to the excessive demand for antibiotics in the last half-century, and, as expected, antibiotic-resistant strains of bacteria developed within a year of introduction of penicillin in clinical settings [1]. It is now well known that antibiotics must be used with caution to ensure that the chemotherapeutic advantages of antibiotics against microbial infections are retained. However, to maximize these advantages, other approaches to microbial disinfection must be adopted in combination with the conventional methods [2].

Antimicrobial photodynamic therapy (APDT) is an alternative therapy indicated for the treatment of microbial infections. APDT has now been in application for over 1000 years across Egypt, India, and China; however, only few researches had been conducted on it until the 1960s. Using microbial cells, Oskar Raab and Hermann Von Tappiener made the first demonstration over 100 years ago when they noticed that cells of Paramecium spp. stained with acridine orange were destroyed upon exposure to bright light. Since then, APDT has primarily been developed as a treatment for cancer, ophthalmological disorders, and for use in dermatology. However, in recent years, interest in the antimicrobial effects of APDT has been revived due to the rapid emergence of antibiotic resistance among pathogenic bacteria. Moreover, APDT has been proposed as a therapy for a large variety of localized microbial infections [3-7].

APDT provides significant advantages over the existing antimicrobial therapies. It appears to be equally effective at killing both multi-drug resistant microbes as well as native bacterial strains. Furthermore, the effect of APDT on microorganisms is much more rapid as compared to that of other antimicrobial agents, and there is no evidence of APDT resistance until date [8].

\section{Mechanism of Action}

The APDT technique uses a non-toxic compound to cause cell death, a process called lethal photosensitization, in which microbial cells are pre-impregnated with a photosensitizer dye (PS) and subsequently exposed to a specific source of light [9-12]. After sensitization, the dye deposited on the target organisms transforms molecular oxygen into reactive oxygen species (ROS), which impart cytotoxic effect on microbial cells. During this process, the components of the PS, on exposure to a specific wavelength of light, acquire an excited state through the transition of electrons to a higher energy level. In this excited state, the PS can interact with molecular oxygen to initiate the formation of ROS (process type II) or interact with other molecules as an electron acceptor to produce hydroxyl radicals and other organic radicals (process type I) [13-17]. The products generated in these reactions can cause various damages to the components of the microbial cells or can alter their metabolic activities irreversibly, thus resulting in death [18]. In general, the principle of the therapy is that the energy absorbed via intracellular photosensitization is transferred to the oxygen molecule to cause severe damage to the oxidative reaction pathways [19] in the plasma membrane and to the genetic materials of the microbial cells, without exerting any toxic effects on the host cells themselves [16].

The basic principles of APDT are relatively simple and assure reliability and efficiency. This technique can be highly effective if it is ensured that, during the execution of phototherapy, all the necessary components, i.e., the dye, oxygen, and light, are present in sufficient amounts to cause damage to the target cells [20]. 


\section{Light Sources}

In health care and management, laser light therapy is increasingly being used in routine clinical practice, mainly because of the advancement in the laser application techniques and improvement in fiber-optic technology. The technological development requires a convergence of researchers from diverse fields, including optical physics, engineering, biochemistry, pharmacology, and the different sectors of health care [21].

The first light source used in APDT was the conventional bulb. However, these bulbs did not yield good results owing to the characteristic of polychromaticity, strong thermal component, and incoherency. Various wavelengths of light are used in order to excite the photosensitizer molecules, including the most commonly used source light amplification by stimulated emission of radiation (laser) and light emitting diode (LED) [9,20,22-25].

Laser is an exceptional source of radiation that is capable of producing extremely fine spectral bands, intense, coherent electromagnetic fields extending from the near infrared to ultraviolet [26], whose light color depends on its wavelength. Shorter wavelengths emit violet light of different variations until the displayed red light is in longer wavelengths. The emitted laser light is characterized by the ever-present electromagnetic waves with the same wavelength, direction, frequency, and color that differ from the conventional light with different wavelengths in all directions, which is a result of the combination of several spectra [27].

For the purpose of eliminating the microorganisms, a laser with low power or low intensity that typically operates with a power of $\leq 100$ $\mathrm{mV}$ and that may produce energy in the visible spectrum (400-700$\mathrm{nm}$ wavelength) either in the ultraviolet $(200-400 \mathrm{~nm})$ or the near infrared $(700-1500 \mathrm{~nm})$ regions should be used. The first low-intensity lasers used, as the active medium, a gas mixture of helium and neon (HeNe laser) emitted in the red spectrum $(632.8 \mathrm{~nm})$. Presently, a vast majority of lasers use a crystal of semiconductor diode of gallium arsenide (GaAs) produced in the laboratory, which can be doped with various other elements, depending on the desired intensity or the intended purpose [28-30].

LEDs are another alternative for the use of APDT. This device has a semiconductor active medium that emits visible light when energized; this light is formed when a certain voltage is applied between layers of semiconductor dopants [31]. Although not monochromatic like lasers, LEDs are capable of producing a high intensity of a broad-spectral band. In the LED, light wave can be produced in various lengths and in adequate power, although laser has a greater light penetration capacity into the tissue [32]. In addition to its relatively low cost and great versatility, LEDs can be arranged in various ways and in large quantity for irradiation of large areas [33].

\section{Photosensitizers}

The APDT technique requires the presence of a PS (preferably located on the target to be treated), a light source, and tissue molecular oxygen. Although several photosensitizing molecules are naturally present as components of cells and tissues, in APDT, these molecules must first be introduced on the treatment area to bind to the target cells. An ideal PS should have low toxicity to host cells when not activated by the light. It should have a pure composition, a stable shelflife, be soluble in water or in a mixture of non-toxic aqueous solvents, and produce a high amount of ROS in a short period of illumination time $[20,24,25]$.

Not all chemical compounds are photosensitizers. Most photosensitive molecules have a heterocyclic ring similar to that present in the chlorophyll and hemoglobin molecules, justifying the fact that, when these molecules are exposed to light, the light energy is captured and subsequently transferred to other molecules, resulting in the release of ROS, which in turn interact with the biological systems and cause tissue damage. In addition, not every substance that can absorb light can act as a photosensitizer, as photosensitizers also need to have other important characteristics [34].

Photosensitizers are classified according to their chemical structures into different types as discussed below:

\section{Porphyrins}

Porphyrins are the first generation of PSs consisting of a mixture of monomers, dimers, and oligomers of hematoporphyrin derivatives. Among the various porphyrins, cationic porphyrins are most promising for use as sensitizers in APDT as they absorb light between the wavelengths of 610 and $630 \mathrm{~nm}$ [35]. A positively charged PS tends to move across to the outer membrane via a self-promoted uptake pathway by a mechanism involving the interaction between divalent cations of the compound with the adjacent bacterial lipopolysaccharide (LPS) [36].

\section{Phthalocyanines}

Phthalocyanines are macrocyclic molecules similar to porphyrin with a high structural flexibility; they are well-known photosensitizers. These compounds are more intensely absorbed in the near infrared region as compared to the original porphyrins due to their aromatic nature. Chloro-aluminum sulfonated phthalocyanine is a phthalocyanine derivative that has an increased aromatic character and therefore lower sensitivity and toxicity to the skin when exposed to ambient light; its higher photosensitivity leads to greater toxicity in the cells on exposure to red light. The advantage of phthalocyanines is the high production of ROS [37-39].

\section{5-aminolevulinic acid (5-ALA)}

5-ALA is a hydrophilic molecule that has limited ability to penetrate through cellular membranes and into the interstitial tissue space. Its application in APDT is based on the accumulation of endogenous protoporphyrin (PpIX), which is a heme precursor that, after topical application, accumulates in tissues with a rapid turnover or in tissues with high cellular activity. The synthesis of ALA is strictly controlled by the ALA synthase enzyme. When ALA is supplied to the cell, it accumulates PpIX and is converted to heme by ferrochelatase on addition of iron to the core of PpIX, presenting a photodynamic effect on exposure to light. The advantage of ALA-induced photosensitization is related to the rapid action of ALA, which limits the risk of photosensitivity $[40,41]$.

\section{Chlorins}

Chlorins exhibit two important properties: high quantum yield of singlet oxygen and intense absorption band at longer wavelengths compared to those by porphyrins, where the biological tissues are most transparent to light $(650-660 \mathrm{~nm})$. The use of chlorins in APDT has 
been shown to be effective and safe, with transient skin photosensitivity reported as the only side effect [34].

\section{Xanthenes}

Xanthenes are cyclic compounds with three aromatic rings in linear arrangement with an oxygen atom in the center, and they are responsible for absorbing light in the visible spectral region. These dyes do not bind to the cell membrane and are located in the cytoplasm. The following compounds belong to this group: rose Bengal, eosin Y, fluorescein, and erythrosin B [42]. Rose Bengal is a halide derivative of fluorescein that is used in ophthalmology as a dye for diagnosis of various diseases. When used in APDT, it can kill microorganisms such as viruses, bacteria, and protozoa. Exposure to light at $532 \mathrm{~nm}$ activates the type II reaction, generating products containing $80 \%$ singlet oxygen and $20 \%$ superoxide anions. An advantage of xanthenes over other photosensitizers is that xanthenes can be orally administered $[16,34,42]$.

\section{Phenothiazines}

Phenothiazines have an absorption band between 600 and $800 \mathrm{~nm}$, which is the most-used wavelength range in APDT. The disadvantage of phenothiazine dyes is their inherent toxicity, which reduces their therapeutic effectiveness. Examples of phenothiazine dyes include methylene blue (MB) and ortho-toluidine blue (TBO) $[16,17,22,23,43-45]$.

MB is a well-known blue dye that was first used as a medicine against malaria. Its mechanism of action includes the interleaving of the $\mathrm{MB}$ cations in the structure of the nucleic acids caused by its positive charge. However, this chromophore is easily reduced in biological systems, which reduces its antibacterial activity. The blue color of an aqueous solution of $\mathrm{MB}$ is due to the fact that the phenothiazinium molecule absorbs visible light strongly in the 600$700 \mathrm{~nm}$ range, thus allowing the remainder of the visible spectrum $(350-600 \mathrm{~nm})$ to be transmitted [16,17,22,23,43-46]. In brief, its mechanism of action includes the breaking of the strands in the organism's nucleic acid structures [47].

TBO, a cationic phenothiazinium dye, has been widely studied for the inactivation of pathogenic microorganisms $[48,49]$. The maximum absorption wavelength is in the red light spectrum of $630 \mathrm{~nm}$, which is capable of inactivating both gram-positive and gram-negative bacteria. This is mainly due to its physical and chemical properties and hydrophilic features that allow its free passage across the bacterial membrane and, consequently, attraction to the negatively charged potential of the mitochondria that allows direct action on this organelle [50-52].

It has been reported earlier that TBO binds to different structural components in gram-positive and gram-negative bacteria. In grampositive bacteria, TBO binds to the teichuronic acid residues of the outer wall [4], whereas, in gram-negative bacteria, it predominantly binds to the LPS present in the outer cell envelope [53,54].

\section{Triarylmethanes}

Another substance that can be used as a photosensitizer is malachite green, a cationic dye of the triarylmethane family, including crystal violet. This dye shows strong absorption in the red region of the visible spectrum [55] and crosses the cell wall of gram-positive and gramnegative microorganisms [56].

\section{New dyes}

Currently, a new dye called curcumin is being extensively studied. Curcumin is a natural yellow pigment extracted from the rhizomes of Curcuma longa and presents a wide range of pharmacological effects including anti-inflammatory, anti-carcinogenic, and anti-infection effects $[57,58]$. Curcumin absorbs light in the blue wavelength range $(300-500 \mathrm{~nm})$ of the visible spectrum. Blue light has a lower penetration depth as compared with red light, due to scattering and absorption of the light by biomolecules; therefore, the use of curcumin in APDT is restricted to topical use for treating superficial wounds [59].

Several studies have reported the successful photokilling action of curcumin in APDT on activation with appropriate light sources [60,61]. In addition, affordable cost, ease of handling, and effectiveness are the major advantages of this PS. However, its solubility in water is highly limited, and it requires the use of oils and synthetic solvents to facilitate its dissolution in water $[62,63]$.

\section{Possible Applications}

The most promising therapeutic possibilities employing APDT is the eradication of microorganisms in certain types of infections, especially in cases of localized superficial infections and those of known microorganisms as an alternative to the use of traditional antimicrobial agents in treatments [64-68].

The bactericidal action of this new therapeutic option has been evidenced in different microorganisms including Porphyromonas gingivalis, Prevotella intermedia, Actinobacillus actinomycetemcomitans, Bacteroides forsythus, Staphylococcus aureus, Streptococcus pneumoniae, Enterococcus faecalis, Haemophilus influenzae, Escherichia coli, Candida albicans, Pseudomonas aeruginosa, Fusobacterium nucleatum, and Streptococcus sanguis, with superior results seen in black-pigmented bacteria owing to their natural chromophores $[69,70]$.

Gram-positive bacteria are less affected than gram-negative bacteria, as the latter are significantly more resistant to several commonly used PS in APDT as well as to the action of singlet oxygen. This difference is due to the structure and components of the cellular envelope of gram-negative bacteria, which present a complex outer membrane with lipid bilayers serving as a physical and functional barrier between the cell and its environment. However, this membrane can form a chemical trap, since this layer is rich in fatty acids and proteins that can react with singlet oxygen. However, the LPS and outer membrane of gram-negative bacteria restrict the lethal effect of singlet oxygen as these cell components can be removed without causing cell death $[54,71]$.

The interest in efficient fungicide treatments has been increasing recently due to the increase in the number of fungal pathogens implicated in the high occurrence of nosocomial infections or due to the increase in the opportunistic mycoses in immunocompromised patients. Unfortunately, insurance and fungi-specific agents are scarce, and most agents are only fungistatic, i.e., they do not cause death, but only inhibit cell multiplication. In addition, the routine use of antibiotics can lead to gradual emergence of resistant strains [72]. The main targets of antibiotics are pathogenic or potentially pathogenic fungi such as Aspergillus fumigatus, Trichophyton rubrum, and especially $C$. albicans, which are a common resident of the mouth, throat, digestive tract, and skin. In hosts with a compromised immune 
system, $C$. albicans can become pathogenic; therefore, oropharyngeal candidiasis is one of the opportunistic infections that may affect acquired immunodeficiency syndrome (AIDS) patients [73]. The resistance of $C$. albicans against fluconazole, a commonly used antifungal agent for these patients, has emerged [74].

Recently, it was shown that Helicobacter pylori naturally accumulate sufficient porphyrin to allow photoinactivation by blue light. This pathogenic bacterium causes endemic gastroduodenal ulcerations in humans, and it is linked to the development of stomach cancer. The emergence of resistance to antibiotics in conventional therapy has been reported for $H$. pylori. In a preliminary clinical trial, when the gastric cells of 13 patients orally administered with ALA were exposed to a blue laser coupled to an endoscope, this microorganism was found to be successfully eradicated $[3,34,75]$. Some studies have revealed that APDT is effective in the treatment of localized viral infections. APDT has been shown to be particularly effective in the treatment of human papilloma virus (HPV) infections $[76,77]$.

The human herpes simplex virus (HSV) is among the most common agents responsible for viral infections in humans and is often associated with serious clinical symptoms, especially in immunocompromised patients, pregnant women, and newborns. The emerging resistance of the virus to the conventional antiviral drugs and the side effects of these drugs are the main reasons for the search of effective and less aggressive novel therapeutic alternatives $[78,79]$.

Human pathogenic parasites can also be killed by the combination of PS and light. Plasmodium falciparum, which is responsible for causing malaria, can be killed by APDT with a $\mathrm{N}$-(4-butanol) pheophorbide derivative and silicon phthalocyanines such as Pc4 [80]. The parasite responsible for Chagas disease, Trypanosoma cruzi, can also be killed by using a combination of light and photosensitizers such as hematoporphyrin and phthalocyanine [81]. In addition, human helminth eggs in sewage can be inactivated by a mesosubstituted cationic porphyrin and light [82].

It should be emphasized that this approach may not be amenable to the treatment of localized infection in few areas of the body. While the actual range of suitable presentations can be appreciated only through increased use and concomitant development of clinical APDT, it can be assumed that this technique could have positive outcomes via local application of both the photosensitizer and illumination through procedures such as endoscopy and use of fiber optics. While it has often been assumed that only topical (i.e., external) application is effective, the phototreatment against infections in the nares, paranasal sinuses, lungs, and gastrointestinal tract has also been reported $[83,84]$.

\section{Future Prospects}

So far, there exists no evidence of resistance to APDT. Therefore, this technique is expected to become extremely important in the near future, that is, after the "antibiotic era" comes to an end $[3,34]$. Caminos e Durantini [13] reported another advantage of APDT-the PSs used can be made selective for a target microorganism by using a combination of a specific drug and low doses of light, and the same effect can be exerted on animal cells by using higher doses of the drug and different concentrations of the PS. The author reported that none of the PSs tested so far have resulted in mutagenic activity or development of drug-resistant strains.
With respect to the potential clinical use of APDT, Bisland et al. [85] reported that its versatility, optimized drug-light regimens, stateof-the-art light sources, and interstitial placement of optical fibers for light delivery might allow the development of a therapy superior to that offered by antibiotics. APDT is applied specifically at the site of infection, thus minimizing the risk of collateral damage to the "friendly" host flora, which can occur with the systemic use of antibiotics. The technique can also be easily customized in real time according to the specific stage and severity of the infection.

However, APDT technique has also been applied to several nonconventional purposes. Blood decontamination by APDT is currently being studied as an effective method of sterilization for the preparation of red blood cell concentrates. On the other hand, the photodynamic treatment of suspensions of red blood cells may result in undesirable hemolysis during extended periods of storage at $1-6^{\circ} \mathrm{C}$ $[86,87]$.

The purification of contaminated water using solar radiation in the presence of PS and dissolved oxygen can lead to degradation of pesticides as well as the death of microorganisms. However, a limitation of this treatment system is the need to remove the PS dissolved in water after the treatment $[88,89]$.

Antimicrobial treatment of food with APDT is being explored considering that the latest methods used for bacterial control in food are not always sufficiently efficient and entirely risk-free for humans and the environment. Non-thermal technologies can alter the structure of proteins and polysaccharides, causing changes in the texture, physical appearance, and functionality of the treated food. APDT has been proposed as a method of inactivation of microorganisms associated with food-borne illnesses; moreover, it is economical and environmentally friendly owing to the fact that it involves the use of non-toxic elements and induces complete destruction of the target microorganisms [90,91].

Other possible future application of APDT is in the production of anti-infective medical devices and surfaces [92-95] and pathogen inactivation in fish farming [96].

\section{Conclusions}

Based on the studies conducted so far, it can be inferred that APDT gives significant results in the elimination of microorganisms in localized infections in different diseases. However, considering the lack of consensus among researchers regarding the concentration of PS and the ideal light dose to be used for safe and effective clinical application of APDT, further studies are required to establish an optimal protocol for implementing this new therapy. Undoubtedly, APDT has great importance in the near future not only for the treatment of infections but also in non-clinical applications in diverse fields.

\section{References}

1. McBain AJ, Gilbert P (2001) Biocide tolerance and the harbingers of doom. Int Biodeterior Biodegrad 47: 55-61.

2. Wainwright M, Crossley KB (2004) Photosensitizing agents circumventing resistance and breaking down biofilms: a review. Int Biodeterior Biodegrad 53: 119-26.

3. Hamblin MR, Hasan $T$ (2004) Photodynamic therapy: a new antimicrobial approach to infectious disease? Photochem Photobiol Sci 3: 436-450. 
4. Jori G (2006) Photodynamic therapy of microbial infections: state of the art and perspectives. J Environ Pathol Toxicol Oncol 25: 505-519.

5. St Denis TG, Dai T, Izikson L, Astrakas C, Anderson RR, et al. (2011) All you need is light: antimicrobial photoinactivation as an evolving and emerging discovery strategy against infectious disease. Virulence 2: 509-520.

6. Zeina B, Greenman J, Purcell WM, Das B (2001) Killing of cutaneous microbial species by photodynamic therapy. Br J Dermatol 144: 274-278.

7. Kashef N, Ravaei Sharif Abadi G, Djavid GE (2012) Phototoxicity of phenothiazinium dyes against methicillin-resistant Staphylococcus aureus and multi-drug resistant Escherichia coli. Photodiagnosis Photodyn Ther 9: 11-15.

8. Dai T, Tegos GP, Zhiyentayev T, Mylonakis E, Hamblin MR (2010) Photodynamic therapy for methicillin-resistant Staphylococcus aureus infection in a mouse skin abrasion model. Lasers Surg Med 42: 38-44.

9. Yildirim C, Karaarslan ES, Ozsevik S, Zer Y, Sari T, et al. (2013) Antimicrobial efficiency of photodynamic therapy with different irradiation durations. Eur J Dent 7: 469-473.

10. Späth A, Leibl C, Cieplik F, Lehner K, Regensburger J, et al. (2014) Improving photodynamic inactivation of bacteria in dentistry: highly effective and fast killing of oral key pathogens with novel tooth-colored type-II photosensitizers. J Med Chem 57: 5157-5168.

11. Javed F, Samaranayake LP, Romanos GE (2014) Treatment of oral fungal infections using antimicrobial photodynamic therapy: a systematic review of currently available evidence. Photochem Photobiol Sci 13: 726-34.

12. Almeida J, Tomé JP, Neves MG, Tomé AC, Cavaleiro JA, et al. (2014) Photodynamic inactivation of multidrug-resistant bacteria in hospital wastewaters: influence of residual antibiotics. Photochem Photobiol Sci 13: 626-33.

13. Caminos DA, Durantini EN (2006) Photodynamic inactivation of Escherichia coli immobilized on agar surfaces by a tricationic porphyrin. Bioorg Med Chem 14: 4253-4259.

14. Lambrechts SA, Aalders MC, Van Marle J (2005) Mechanistic study of the photodynamic inactivation of Candida albicans by a cationic porphyrin. Antimicrob Agents Chemother 49: 2026-2034.

15. Metcalf D, Robinson C, Devine D, Wood S (2006) Enhancement of erythrosine-mediated photodynamic therapy of Streptococcus mutans biofilms by light fractionation. J Antimicrob Chemother 58: 190-192.

16. Wood S, Metcalf D, Devine D, Robinson C (2006) Erythrosine is a potential photosensitizer for the photodynamic therapy of oral plaque biofilms. J Antimicrob Chemother 57: 680-684.

17. Zanin IC, Gonçalves RB, Junior AB, Hope CK, Pratten J (2005) Susceptibility of Streptococcus mutans biofilms to photodynamic therapy: an in vitro study. J Antimicrob Chemother 56: 324-330.

18. Hamblin MR, O'Donnell DA, Murthy N, Rajagopalan K, Michaud N, et al. (2002) Polycationic photosensitizer conjugates: effects of chain length and Gram classification on the photodynamic inactivation of bacteria. J Antimicrob Chemother 49: 941-951.

19. Munin E, Giroldo LM, Alves LP, Costa MS (2007) Study of germ tube formation by Candida albicans after photodynamic antimicrobial chemotherapy (PACT). J Photochem Photobiol B 88: 16-20.

20. Castano AP, Demidova TN, Hamblin MR (2004) Mechanisms in photodynamic therapy. Part one. Photosensitizers, photochemistry and cellular localization. Photodiagn Photodyn Ther 1: 279-93.

21. Shackley DC, Whitehurst C, Clarke NW, Betts C, Moore JV (1999) Photodynamic therapy. J R Soc Med 92: 562-565.

22. Giusti JS, Santos-Pinto L, Pizzolito AC, Helmerson K, Carvalho-Filho E, et al. (2008) Antimicrobial photodynamic action on dentin using a lightemitting diode light source. Photomed Laser Surg 26: 281-287.

23. Mima EG, Pavarina AC, Ribeiro DG, Dovigo LN, Vergani CE, et al. (2011) Effectiveness of photodynamic therapy for the inactivation of Candida spp. on dentures: in vitro study. Photomed Laser Surg 29: 827-833.
24. Meisel P, Kocher T (2005) Photodynamic therapy for periodontal diseases: state of the art. J Photochem Photobiol B 79: 159-170.

25. Junqueira JC, Ribeiro MA, Rossoni RS, Barbosa JO, Querido et al. (2010) Antimicrobial photodynamic therapy: photodynamic antimicrobial effects of malachite green on Staphylococcus, Enterobacteriaceae, and Candida. Photomed Laser Surg 28: S67-S72.

26. Damante CA, Greghi SL, Sant'ana AC, Passanezi E (2004) Clinical evaluation of the effects of low-intensity laser (GaAlAs) on wound healing after gingivoplasty in humans. J Appl Oral Sci 12: 133-136.

27. Coluzzi DJ, Goldestein AJ (2005) Lasers in dentistry. An overview. Dent Today 23: 120-7.

28. Silva Garcez A, Núñez SC, Lage-Marques JL, Jorge AO, Ribeiro MS (2006) Efficiency of $\mathrm{NaOCl}$ and laser-assisted photosensitization on the reduction of Enterococcus faecalis in vitro. Oral Surg Oral Med Oral Pathol Oral Radiol Endod 102: e93-98.

29. Gutknecht N, Franzen R, Vanweersch JML, Mir M (2005) Temperature evolution on human teeth root surface after diode laser assisted endodontic treatment. Lasers Med Sci 20: 99-103.

30. Matevski D, Weersink R, Tenenbaum HC, Wilson B, Ellen RP, et al. (2003) Lethal photosensitization of periodontal pathogens by a redfiltered Xenon lamp in vitro. J Periodontal Res 38: 428-435.

31. Ee HL, Barlow RJ (2007) Lasers, lights and related technologies: a review of recent journal highlights. Clin Exp Dermatol 32: 135-137.

32. Pagin MT, de Oliveira FA, Oliveira RC, Sant'Ana AC, de Rezende ML, et al. (2014) Laser and light-emitting diode effects on pre-osteoblast growth and differentiation. Lasers Med Sci 29: 55-59.

33. Asai T, Suzuki H, Kitayama M, Matsumoto K, Kimoto A, et al. (2014) The long-term effects of red light-emitting diode irradiation on the proliferation and differentiation of osteoblast-like MC3T3-E1 cells. Kobe J Med Sci 60: E12-18.

34. Perussi JR (2007) Inativação fotodinâmica de microrganismos. Quim Nova 30: 988-94.

35. Schastak S, Ziganshyna S, Gitter B, Wiedemann P, Claudepierre T (2010) Efficient photodynamic therapy against gram-positive and gram-negative bacteria using THPTS, a cationic photosensitizer excited by infrared wavelength. PLoS ONE 5: e11674.

36. Nitzan Y, Gozhanski S, Malik Z (1983) Effect of photoactivated hematoporphyrin derivative on the viability of Staphylococcus aureus. Curr Micro 8: 279-284.

37. Mikula P, Kalhotka L, Jancula D, Zezulka S, Korinkova R, et al. (2014) Evaluation of antibacterial properties of novel phthalocyanines against Escherichia coli - Comparison of analytical methods. J Photochem Photobiol B 138: 230-239.

38. Bicalho LS, Longo JP, Cavalcanti CE, Simioni AR, Bocca AL, et al. (2013) Photodynamic therapy leads to complete remission of tongue tumors and inhibits metastases to regional lymph nodes. J Biomed Nanotechnol 9: $811-818$

39. Horne TK, Abrahamse H, Cronjé MJ (2012) Investigating the efficiency of novel metallo-phthalocyanine PDT-induced cell death in MCF-7 breast cancer cells. Photodiagnosis Photodyn Ther 9: 215-224.

40. Gold MH (2009) Therapeutic and aesthetic uses of photodynamic therapy part five of a five-part series: ALA-PDT and MAL- PDT what makes them different. J Clin Aesthet Dermatol 2: 44-47.

41. Ko DY, Kim KH, Song KH (2014) Comparative Study of Photodynamic Therapy with Topical Methyl Aminolevulinate versus 5-Aminolevulinic Acid for Facial Actinic Keratosis with Long-Term Follow-Up. Ann Dermatol 26: 321-331.

42. Schäfer M, Schmitz C, Facius R, Horneck G, Milow B, et al. (2000) Systematic study of parameters influencing the action of Rose Bengal with visible light on bacterial cells: comparison between the biological effect and singlet-oxygen production. Photochem Photobiol 71: 514-23.

43. Zanin IC, Lobo MM, Rodrigues LK, Pimenta LA, Höfling JF, et al. (2006) Photosensitization of in vitro biofilms by toluidine blue $\mathrm{O}$ combined with a light-emitting diode. Eur J Oral Sci 114: 64-69. 
44. Konopka K, Goslinski T (2007) Photodynamic therapy in dentistry. J Dent Res 86: 694-707.

45. Ragàs X, Sánchez-García D, Ruiz-González R, Dai T, Agut M, et al. (2010) Cationic porphycenes as potential photosensitizers for antimicrobial photodynamic therapy. J Med Chem 53: 7796-7803.

46. Wainwright M (2000) Methylene blue derivatives--suitable photoantimicrobials for blood product disinfection? Int J Antimicrob Agents 16: 381-394.

47. Menezes S, Capella MA, Caldas LR (1990) Photodynamic action of methylene blue: repair and mutation in Escherichia coli. J Photochem Photobiol B 5: 505-517.

48. Sharma M, Visai L, Bragheri F, Cristiani I, Gupta PK, et al. (2008) Toluidine blue-mediated photodynamic effects on staphylococcal biofilms. Antimicrob Agents Chemother 52: 299-305.

49. Sharma M, Bansal H, Gupta PK (2005) Virulence of Pseudomonas aeruginosa cells surviving photodynamic treatment with toluidine blue. Curr Microbiol 50: 277-280

50. Nagata JY, Hioka N, Kimura E, Batistela VR, Terada RS, et al. (2012) Antibacterial photodynamic therapy for dental caries: evaluation of the photosensitizers used and light source properties. Photodiagnosis Photodyn 9: 122-31.

51. Rolim JP, de-Melo MA, Guedes SF, Albuquerque-Filho FB, Souza JR et al. (2012) The antimicrobial activity of photodynamic therapy against Streptococcus mutans using different photosensitizers. J Photochem Photobiol B 106: 40-6.

52. Ito T (1983) Photodynamic agents as tools for cell biology. Photochem Photobiol Rev 7: 141-86.

53. Usacheva MN, Teichert MC, Biel MA (2003) The role of the methylene blue and toluidine blue monomers and dimers in the photoinactivation of bacteria. J Photochem Photobiol B 71: 87-98.

54. Usacheva MN, Teichert MC, Biel MA (2001) Comparison of the methylene blue and toluidine blue photobactericidal efficacy against gram-positive and gram-negative microorganisms. Lasers Surg Med 29: 165-173.

55. Yamaoka K, Sasai R (2000) Pulsed Electric Linear Dichroism of Triphenylmethane Dyes Adsorbed on Montmorillonite K10 in Aqueous Media. J Colloid Interface Sci 225: 82-93.

56. Kowaltowski AJ, Turin J, Indig GL, Vercesi AE (1999) Mitochondrial effects of triarylmethane dyes. J Bioenerg Biomembr 31: 581-590.

57. Gupta KK, Bharne SS, Rathinasamy K, Naik NR, Panda D (2006) Dietary antioxidant curcumin inhibits microtubule assembly through tubulin binding. FEBS J 273: 5320-5332.

58. Ruby AJ, Kuttan G, Babu KD, Rajasekharan KN, Kuttan R (1995) Antitumour and antioxidant activity of natural curcuminoids. Cancer Lett 94: 79-83.

59. Hegge AB, Nielsen TT, Larsen KL, Bruzell E, Tønnesen HH (2012) Impact of curcumin supersaturation in antibacterial photodynamic therapy--effect of cyclodextrin type and amount: studies on curcumin and curcuminoides XLV. J Pharm Sci 101: 1524-1537.

60. Bruzell EM, Morisbak E, Tønnesen HH (2005) Studies on curcumin and curcuminoids. XXIX. Photoinduced cytotoxicity of curcumin in selected aqueous preparations. Photochem Photobiol Sci 4: 523-530.

61. Dujic J, Kippenberger S, Ramirez-Bosca A, Diaz-Alperi J, Bereiter-Hahn $\mathrm{J}$, et al. (2009) Curcumin in combination with visible light inhibits tumor growth in a xenograft tumor model. Int J Cancer 124: 1422-1428.

62. Dovigo LN, Pavarina AC, Ribeiro AP, Brunetti IL, Costa CA, et al. (2011) Investigation of the photodynamic effects of curcumin against Candida albicans. Photochem Photobiol 87: 895-903.

63. Araújo NC, Fontana CR, Bagnato VS, Gerbi ME (2012) Photodynamic effects of curcumin against cariogenic pathogens. Photomed Laser Surg 30: 393-399.

64. Garcez AS, Ribeiro MS, Tegos GP, Núñez SC, Jorge AOC, et al. (2007) Antimicrobial photodynamic therapy combined with conventional endodontic treatment to eliminate root canal biofilm infection. Lasers Surg Med 39: 59-66.
65. Feuerstein O, Moreinos D, Steinberg D (2006) Synergic antibacterial effect between visible light and hydrogen peroxide on Streptococcus mutans. J Antimicrob Chemother 57: 872-876.

66. Soukos NS, Chen PS, Morris JT, Ruggiero K, Abernethy AD, et al. (2006) Photodynamic therapy for endodontic disinfection. J Endod 32: 979-984.

67. Wainwright M (2014) In defence of 'dye therapy'. Int J Antimicrob Agents 44: 26-29.

68. Jori G, Brown SB (2004) Photosensitized inactivation of microorganisms. Photochem Photobiol Sci 3: 403-405.

69. Wilson M (1994) Bactericidal effect of laser light and its potential use in the treatment of plaque-related diseases. Int Dent J 44: 181-189.

70. Almeida JM, Garcia VG, Theodoro LH (2006) Terapia fotodinâmica: uma opção na terapia periodontal. Arq Odontol 42: 199-210.

71. Kömerik N, Wilson M, Poole S (2000) The effect of photodynamic action on two virulence factors of gram-negative bacteria. Photochem Photobiol 72: 676-680.

72. Gulat S, Doluca Dereli M (2014) Investigation of the expression levels of efflux pumps in fluconazole-resistant Candida albicans isolates. Mikrobiyol Bul 48: 325-334.

73. Katano H, Hishima T, Mochizuki M, Kodama Y, Oyaizu N, et al. (2014) The prevalence of opportunistic infections and malignancies in autopsied patients with human immunodeficiency virus infection in Japan. BMC Infect Dis 14: 229.

74. Dos Santos Abrantes PM, McArthur CP, Africa CW (2014) Multi-drug resistant oral Candida species isolated from HIV-positive patients in South Africa and Cameroon. Diagn Microbiol Infect Dis 79: 222-227.

75. Ganz RA, Viveiros J, Ahmad A, Ahmadi A, Khalil A, et al. (2005) Helicobacter pylori in patients can be killed by visible light. Lasers Surg Med 36: 260-265.

76. Soergel P, Dahl GF, Onsrud M, Hillemanns P (2012) Photodynamic therapy of cervical intraepithelial neoplasia 1-3 and human papilloma virus (HMV) infection with methylaminolevulinate and hexaminolevulinate--a double-blind, dose-finding study. Lasers Surg Med 44: 468-74.

77. Lee RG, Vecchiotti MA, Heaphy J, Panneerselvam A, Schluchter MD, et al. (2010) Photodynamic therapy of cottontail rabbit papillomavirusinduced papillomas in a severe combined immunodeficient mouse xenograft system. Laryngoscope 120: 618-24.

78. Makarov OV, Khashukaeva AZ, Svitich OA, Markova ĖA, Khlynova SA, et al. (2014) Anti-herpetic effect of photodynamic action in an in vitro experiment. Zh Mikrobiol Epidemiol Immunobiol : 48-55.

79. Marotti J, Aranha AC, Eduardo Cde P, Ribeiro MS (2009) Photodynamic therapy can be effective as a treatment for herpes simplex labialis. Photomed Laser Surg 27: 357-363.

80. Baptista MS, Wainwright M (2011) Photodynamic antimicrobial chemotherapy (PACT) for the treatment of malaria, leishmaniasis and trypanosomiasis. Braz J Med Biol Res 44: 1-10.

81. Gottlieb P, Shen LG, Chimezie E, Bahng S, Kenney ME, et al. (1995) Inactivation of Trypanosoma cruzi trypomastigote forms in blood components by photodynamic treatment with phthalocyanines. Photochem Photobiol 62: 869-874.

82. Wainwright M, Baptista MS (2011) The application of photosensitisers to tropical pathogens in the blood supply. Photodiagnosis Photodyn Ther 8: 240-248.

83. Biel MA, Pedigo L, Gibbs A, Loebel N (2013) Photodynamic therapy of antibiotic-resistant biofilms in a maxillary sinus model. Int Forum Allergy Rhinol 3: 468-473.

84. Millson CE, Wilson M, MacRobert AJ, Bown SG (1996) Ex-vivo treatment of gastric Helicobacter infection by photodynamic therapy. J Photochem Photobiol B 32: 59-65.

85. Bisland SK, Chien C, Wilson BC, Burch S (2006) Pre-clinical in vitro and in vivo studies to examine the potential use of photodynamic therapy in the treatment of osteomyelitis. Photochem Photobiol Sci 5: 31-38.

86. Solheim BG (2008) Pathogen reduction of blood components. Transfus Apher Sci 39: 75-82. 
Citation: Rosa LP, da Silva FC (2014) Antimicrobial Photodynamic Therapy: A New Therapeutic Option to Combat Infections. J Med Microb

87. Wainwright M, Mohr H, Walker WH (2007) Phenothiazinium derivatives for pathogen inactivation in blood products. J Photochem Photobiol B 86: 45-58.

88. Devipriya S, Yesodharan S (2005) Photocatalytic degradation of pesticide contaminants in water. Solar Energy Mater Sol Cells 86: 309-348.

89. Carvalho CMB, Tome JPC, Faustino MAF, Neves M, Tome AC, et al. (2009) Antimicrobial photodynamic activity of porphyrin derivatives Potential application on medical and water disinfection. J Porphyr Phthalocyanines 13: 574-577.

90. Luksiene Z, Zukauskas A (2009) Prospects of photosensitization in control of pathogenic and harmful micro-organisms. J Appl Microbiol 107: 1415-1424.

91. Luksiene Z, Paskeviciute E (2011) Novel approach to the microbial decontamination of strawberries: chlorophyllin-based photosensitization. J Appl Microbiol 110: 1274-1283.

92. Parsons C, McCoy CP, Gorman SP, Jones DS, Bell SE, et al. (2009) Antiinfective photodynamic biomaterials for the prevention of intraocular lens-associated infectious endophthalmitis. Biomaterials 30: 597-602.
93. Baroli B (2007) Hydrogels for tissue engineering and delivery of tissueinducing substances. J Pharm Sci 96: 2197-2223.

94. Funes MD, Caminos DA, Alvarez MG, Fungo F, Otero LA, et al. (2009) Photodynamic properties and photoantimicrobial action of electrochemically generated porphyrin polymeric films. Environ Sci Technol 43: 902-908.

95. Decraene V, Pratten J, Wilson M (2008) Novel light-activated antimicrobial coatings are effective against surface-deposited Staphylococcus aureus. Curr Microbiol 57: 269-273.

96. Almeida A, Cunha A, Newton MCM, Alves E, Costa L, et al. (2009) Phage therapy and photodynamic therapy: Low environmental impact approaches to inactivate microorganisms in fish farming plants. Mar Drugs 7: 268-313. 